\title{
Reforms spell optimism for biological research in China
}

\section{A series of government reforms aim to enhance basic research efforts in China with a shift in focus from quantity to quality.}

During the past decade, biological research in China has undergone enormous progress. The fraction of papers listed as 'cell biology' in the Web of Science Core Collection that were contributed by authors based in mainland China increased from 5.7\% to $26.4 \%$ between 2007 and 2016. The growth of research output has been accompanied by enhanced research quality, as reflected by the increased number of studies published in life science journals included in the Nature Index, a database collating author affiliation information from research articles published in an independently selected group of high-quality journals (http://go.nature.com/2wKrTkL). A similar upward trend is notable in the proportion of publications by China-based authors in the top $1 \%$ of the most-cited biology-related papers, which rose from less than $5 \%$ in 2007 to almost $15 \%$ in 2016 based on data from the Essential Science Indicator.

When it comes to the country's science spending, although by 2014 China's overall R\&D expenditure amounted to $2 \%$ of its GDP, only $5 \%$ of that was allocated to basic research (http://go.nature. com/2yaFZQF). However, last year's release of China's thirteenth five-year development plan covering 2016-2020 indicated that basic research funding could triple to $\sim 10 \%$ of the total $\mathrm{R} \& \mathrm{D}$ expenditure by 2020 (http://go.nature.com/2hZqynP). Furthermore, an overhaul of the funding system promises to ensure that efforts to tackle major challenges are well supported by avoiding funding of redundant programmes (http://go.nature.com/2wMNwRF). The new funding system is simplified into five categories: natural science projects supported by the National Natural Science Foundation of China (NSFC), the National Science and Technology (S\&T) Major Project, the National Key Research and Development Plan (NKRDP), the technology innovation plan, and the S\&T talent plan (http://go.nature. com/2wMNwRF). Numerous state-funded programmes, including the ' 973 ' and ' 863 ' projects that used to be important funding sources for biological research (Nat. Rev. Mol. Cell Bio. 14, 600-606; 2013), have now been merged into the NKRDP. Among the 42 initiatives supported by NKRDP this year, the 'stem cell and translational research' and 'protein machineries for life process regulation' categories are closely related to biological research. Under these 2 initiatives, 78 projects were reportedly supported with over CNY 1.6 billion (over US $\$ 240$ million; http://go.nature.com/2yVGwCB and http://go.nature.com/2xwRJIt).

In contrast to the high selectivity and restricted priority principles that characterize the NKRDP, the NSFC features broad coverage of research proposals with $\sim 70 \%$ of its funds allocated to 'blue-skies' projects and will thus remain the major funding resource for biologists in China (http:// go.nature.com/2i3JLVv). Based on its recent five-year development plan, the NSFC is set to continue supporting hypothesis-driven fundamental research (for example, the General Program and the Key Program) and programmes that foster exceptionally talented junior scientists (for example, the National Science Fund for Distinguished Young Scholars).
It will also place additional emphasis on the development of scientific technology and multidisciplinary research efforts (http://go.nature. com/2yUwUIc). The NSFC has increased its programme categories from three, covering research, talent training, and research support, to the current four programmes supporting exploration, talents, tools and convergence aiming to "concentrate on research themes and to promote interdisciplinary research" (http://go.nature.com/2yUwUIc). Of note, the NSFC is posed to implement additional measures to maintain research integrity to ensure high quality of research (Nature 534, 467-469; 2016). For example, in response to the retraction of 107 research papers published in Tumor Biology by Chinese authors, the Chinese government enforced harsh penalties including the cancellation of more than 30 NSFC grant applications (Nature 546, 464; 2017), reflecting its zero tolerance to scientific misconduct.

Another approach to cultivate high-quality work was initiated by the Chinese Academy of Sciences (CAS), the largest research organization in China, comprising over 100 institutes across the country. CAS launched the Pioneer Initiative in 2014, aiming to become a worldclass institute by supporting basic research in frontier science. To that end, the Pioneer Initiative has established nine Centers for Excellence, three of which support biological research on molecular \& cell biology (MCB), brain and plant science. Each centre has one or two CAS institutes as the principal coordinators of multi-source material and human resources to tackle fundamental problems in their respective areas. For example, MCB has gathered talented scientists from CAS to address five critical MCB lines of research: cellular dynamics and structure, signal transduction, genome stability and epigenetics, RNA biology, and new technologies.

Even with sufficient funds and a supportive system in place, talented and visionary individuals remain the key to high-quality research. China has adopted various strategies to recruit such intellectual talents. In 2008, the central government established the Recruitment Program of Global Experts, also known as the Thousand Talents Plan (http://go.nature.com/2zaNchb), aiming to attract top experts from overseas to China over a period of five to ten years. Part of this plan is the Recruitment Program for Young Professionals, which provides awardees with a generous start-up package, ample laboratory space, full professorship and a living allowance (Nat. Rev. Mol. Cell Bio. 14, 600-606; 2013). Since its launch in 2011, this plan has successfully recruited 3,000 early career-stage scientists, building a strong basis for high-quality research output over the next few years.

Will these reforms bring the desired increase in quality and impact to China's biological research? It is too soon to tell. Nevertheless, the current approaches to optimize China's research system through strategic allocation of funds and championing robust, high-quality work by an elite pool of scientists raise optimism for a further boost in China's contributions to biological research. 